\title{
The Value and Development of the Original Ecological Cultural Resources of the Gelao
}

\author{
Jingjing Feng1,2 \\ ${ }^{1}$ College of Marxism, Southwest Jiaotong University, Chengdu, China \\ ${ }^{2}$ College of Chemical Engineering, Guizhou Institute of Technology, Guiyang, China \\ Email: 918715882@qq.com
}

How to cite this paper: Feng, J. J. (2022). The Value and Development of the Original Ecological Cultural Resources of the Gelao. Advances in Anthropology, 12, 1-8. https://doi.org/10.4236/aa.2022.121001

Received: December 7, 2021

Accepted: January 3, 2022

Published: January 6, 2022

Copyright (c) 2022 by author(s) and Scientific Research Publishing Inc. This work is licensed under the Creative Commons Attribution International License (CC BY 4.0).

http://creativecommons.org/licenses/by/4.0/

\begin{abstract}
The Gelao people are rich in original ecological cultural resources, including original ecological residential culture, original ecological sacrificial culture, original ecological wedding custom culture, etc. The article uses semistructured in-depth interviews and experiential observation methods to study the differential value, scarcity value and liveness value of the Gelao people's original ecological cultural resources, aiming to transform the Gelao people's apparent cultural resources from the perspective of tourism development As a direct cultural capital, it will further transform potential resource advantages into obvious development advantages, so that culture can get a new life in development.
\end{abstract}

\section{Keywords}

Gelao People, Original Ecological Culture, Value, Development

\section{Introduction}

The original ecological national culture has great application potential in rural revitalization, so it needs to be studied as a special national cultural content. Green ecology is the greatest wealth, the greatest advantage, and the greatest brand (Xie, 2021). It must be well protected. We must do a good job of managing mountains and waters and revealing mountains and dews, and we will find a way of economic development and ecological civilization that complement each other and complement each other. The article investigated the Gelao settlements of Wuchuan, Daozhen, and Shiqian on the spot. Using semi-structured in-depth interviews, 50 people were interviewed by class and age. After three months of experience and observation in the Gelao settlements, they tried to dig deeper. The modern value of the original ecological culture in the process of promoting 
economic development has made the original ecological culture an important driving force and resource for rural development in ethnic areas.

\section{The Original Ecological Cultural Resources of the Gelao People}

1) The original ecological residential culture of the Gelao people

Gelao people's dwellings are generally small blue-tiled wooden houses built on the top of the mountain with buckets and hanging (Yuan, 2020) on the top of the mountain. Gelao residents generally choose the terrain to face the sun, shelter from the wind and have water sources, and build houses along the gentle slopes of the dam with far-reaching views. They like to live together in groups and form family-style villages.

Inside the dwellings, they are all with a bucket-type frame structure. It is composed of pillars, piers, beams, purlins, and floor pillows. Two components, column and pierced, are arranged in a bucket. From the center pillar to the top of the front and rear eave pillars, it gradually lowers into a sloped shape, which is called "water separation". The main house of the folk house is a main room, and the main room is divided into "flat door" and "concave door". The flat door opens a door directly on the wooden wall in the middle of the front; the concave door folds the front eaves wall of the Ming room inward by one column to form a "swallowing mouth" and opens a door in the middle. The gate is about 2 meters high and 1.2 meters wide. A fixed window is set in the middle of the two side walls of the main house door to facilitate light entering the main house. The hall is a venue for weddings, funerals and ancestor worship of the Gelao tribe. Its area is about 4 meters wider than the two sides. The halls generally do not have floor slabs, which means that the souls of the ancestors come and go freely. The center of the back wall of the hall is a shrine. "Ancient predecessors, site owners" are posted upright in the center of the shrine. Nowadays, I mostly follow the Han custom, and the book "Heaven and Earth Jun Qinshi". The names of the ancestors who passed away are listed on both sides of the front position. A square table is placed next to the wall under the shrine for weddings, funerals, and sacrifices to ancestors.

The Gelao people first look at Feng Shui and choose the foundation for building a house. If someone builds a house in the village, he must first ask the "Master Pu" - that is, Mr. Yin and Yang uses a compass to press his birth date to choose the place to build the house in the village, and then determine the position according to the "Tianzhi Digan" and "Yin and Yang Five Elements". Out of the day when construction started. It is generally believed that the three days of the third, fourteenth, and twenty-fifth of each month are unlucky and it is not suitable to start construction. In fact, it is ground-breaking and stone. When opening the mountain to build the foundation of the house, prepare a rooster, a jug of wine, and a bowl of rice to go to the foundation with the craftsman. After that, the craftsman placed a piece of stone in the location that will become the 
main house, called "anshi". Then the beams will be erected. The upright beam is the most important link in the process of building a house. Houses are generally six rows of columns. Finally, go to the door. It refers to the double door in the middle of the hall where the newly built house is installed. When he comes to the door, he must ask the "Master Pu" to choose auspicious days and auspicious hours.

2) The original ecological sacrificial sacrificial culture of the Gelao people

In order to survive and develop, or to obtain the gifts of nature, the Gelao people can protect their people from prosperity, health and longevity, and adequate food and clothing. They mystify some incomprehensible natural phenomena, or some accidental things, and think that everything is anim, that is Heaven, earth, mountains and rivers, wind, clouds, thunder and lightning, sun, moon and stars all have their own gods. When the Gelao people encounter diseases, disasters, misfortunes, etc., they think that this is caused by all kinds of supernatural ghosts, so they turn to the gods for help, so there are many rituals to sacrifice to the gods. The Gelao people worship the King Bao (Liu, 2021), which is popular in Daping, Zhennan, Baicun, Fengle and other places in the Wuchuan Gelao and Miao Autonomous County. This form is a typical representative of the Gelao Dansha culture. The Wuchuan Gelao people believe in Taoist priests, believing in being a dojo and believing in yin and yang. After the old man passed away, Mr. Taoist must be invited to do the dojo to save the dead soul for the old man. In addition to organizing the funeral and doing the dojo, there is another important link. Mr. Yin Yang is asked to choose the cemetery for the elderly. It is believed that the choice of the old man's house is the key to the success or failure of future generations. If future generations are prosperous, it is because the cemetery is well selected.

Take the "Eating New Festival" with ethnic characteristics of the Gelao tribe as an example. The "Eating New Festival" is the only festival without a fixed date. The previous "New Eating Festival" and rituals were organized in the village. The clan gathering activities were under the auspices of the elders of the clan. The housewives of each family led their daughter-in-laws and daughters to pick new grains and melons and beans in the nearby fields. The ears of the grains should be selected with full ears, and the melons and beans should be picked with the best. No matter who you pick (including foreign nationals), you will not only be free from interference, but the host family can also use the food and vegetables to let you grow. The Gelao ancestors who "opened up wasteland and cleared the grass" received the sacrifice, which was considered a matter of honor and good fortune. After returning home, the male host carefully selected the full-grained rice ears, bundled them into rice bunches, hung them on both sides of the hall, and enshrined them on the table in front of the ancestor's tablet. In some places, the selected grains are put in a retort, steamed, and then sacrificed for seven days in a row. In some places, new grains, fresh melon beans, and other sacrifices were put on the ridge, and then prayed to the ancestors. 
3) The original ecological marriage custom culture of the Gelao people

The marriage customs of the Gelao people have their unique characteristics. In ancient times, the Gelao tribe's marriage was free, and both men and women chose freely. After the reform, especially in the Qing Dynasty, it was all based on the orders of the parents and the matchmakers, and emphasized that they should be right. The Gelao people's marriage customs are relatively cumbersome, and first-time marriages must go through procedures such as proposal, engagement, burning of incense, and marriage.

The proposal takes the man's home (commonly known as the winner) as the initiative. After the son is 10 years old, after the parents see a certain daughter, they invite the matchmaker to propose to the woman's home (commonly known as the loser). Proposal is a temptation at first. The woman's family should make unannounced visits, visit the man's family status, and check her character. The matchmaker will come to the woman's home for the second time before agreeing or disagreeing; the engagement is made by the matchmaker, and after the parents of both parents agree, the man, the family prepares gifts such as eggs, noodles, sweets, etc. The man and the matchmaker go to the woman's house, commonly known as "letting go" (Li, 2013) to show engagement. During this process, the man and woman do not touch and talk, and the woman avoids and occasionally has the opportunity to peek at each other; "insert incense". The male family prepares "letter of appointment", firecrackers, incense candles, eggs, noodles, meat, bracelets, rings, clothing, etc. The gift is more important if the family is in good condition. The bride price is divided into a number of bamboo baskets, and the media leader is invited to give a "burn incense" to the female family. Ceremonies are held more often when choosing auspicious days in the first month; the most important thing is the marriage. The wedding ceremony of the Gelao tribe is onerous, and they also pay attention to it. The Gelao marriage rituals include the procedures of reporting, preparing for marriage, crying for marriage, and marrying. Crying marriage is a unique marriage custom of the Gelao people. One week or three or five days before marriage, the girl should cry for marriage and confide her parting feelings, and the relatives or neighbours should cry with each other and cry to each other. The crying marriage has a musical tune, also known as the crying marriage song.

\section{The Value of the Original Ecological Cultural Resources of the Gelao People}

1) The differential value of the original ecological cultural resources of the Gelao people

Due to the impact of modern lifestyles, the original ecological cultural resources have gradually withdrawn and faded out of our lives. They only exist in some relatively isolated, remote, and impoverished rural areas and ethnic regions, and become scarce resources in rural revitalization. The preciousness of the original ecological cultural resources of the Gelao people lies in this scarcity. 
The value of the original ecological culture of the Gelao nationality as a scarce resource is the value that is highlighted due to scarcity. From an economic analysis, scarcity is an important measure for judging value. Traditional life is about to become the past, a cultural memory of historical times. The original ecological culture of the Gelao ethnic group is a scarce resource. On the one hand, the original ecological culture mainly exists in remote areas, ethnic regions, and ethnic regions. On the other hand, under the impact of globalization, the economic mode of farming will inevitably undergo changes, and the culture attached to the economic mode of farming will inevitably face the fate of disappearance. It can be said that the original ecological culture of the Gelao ethnic group is a kind of scarce and non-renewable cultural resources.

2) The scarcity value of the original ecological cultural resources of the Gelao people

The original ecological culture of the Gelao ethnic group can be regarded as an ancient way of survival that embodies the wisdom of generations of human beings (Cai, 2013). It is a treasure of wisdom for mankind to make survival decisions and adapt to the harsh living environment in a harsh living environment, with a long history of accumulation. And the ancient laws of life have long become human wealth and resources for human progress. Culture develops through communication and competition. Any kind of culture is an effective adaptation to its own living environment. The human living environment is different due to the differences in the ecological environment in which humans live and the differences in coping with the differences in survival methods. This difference determines the differences in human culture. Different regions and different groups of people will form and choose different types. Culture, every kind of culture as a way of human existence has its own value and is a resource for the prosperity and development of society. Modernization is a mainstream of today's social development, and modern culture is a mainstream form in today's cultural process. This is a basic standpoint of the characteristics of current social development, and it is an unavoidable reality. However, globalization and modernization do not mean uniformity. Modern society is a diversified society and a differentiated society. Diversity and diversity have always been the development goals pursued by mankind. Different forms of culture, mainstream culture, non-mainstream culture, and marginal culture can coexist. The pursuit of diversity is to recognize the value of difference. There are differences between the original ecological culture and the global, modern life and modern way. The original ecological culture of the Gelao people, as an ancient way of survival in the farming society, can provide people in modern society with a brand new life experience and survival experience, which is very different from the modern way of living in industrial society that takes the commodity economy as the main form. In the fast-paced and competitive modern society, the leisurely, soothing, and simple life in the original ecological culture is a huge contrast. There is a huge difference between the original ecological culture and modern culture of 
Gelao people.

3) The living value of the original ecological cultural resources of the Gelao people

The original ecological ethnic culture of the Gelao ethnic group is the coupling operation of the Gelao ethnic culture, nature and ecosystem, emphasizing the systematic analysis of synchronicity. A static, lack of fluidity culture will not develop, and culture can only achieve sustained development if it plays a role in continuous use and continuous adaptation to the environment. The original ecological culture of the Gelao ethnic group is an ancient way of life, but the ancient way of life it presents can be maintained in the course of thousands of years of historical development. It must be admitted that it is a kind of survival that adapts to the environment. The way is tenacious. Culture is an ongoing form of life, the way of human existence, and primitive culture is an ongoing form of ancient life, a way of survival in the early days of human farming. As a way of living and way of life, the original ecological culture of the Gelao people is closely related to human life practice, human existence, and human actual life. It is an external aspect of human life and life. The appearance is a living and living cultural form (Yu, 2011). The original ecological culture of the Gelao ethnic group is an ancient cultural form with strong vitality. In the process of cultural generation and development, the original ecological culture has the meaning of living fossils.

\section{Development of the Original Ecological Cultural Resources of the Gelao People}

The process of maintaining and protecting the "proto-ecological culture" is a process of merging multiple subjects and ideas, and is the overall presentation after the collision of social structure and historical practice (Huang, 2017). The development of the original ecological cultural resources of the Gelao nationality mainly refers to the development of tourism. As a kind of resource, the original ecological culture is of decisive significance in the development of tourism, especially in the development of national tourism. To a large extent, ethnic tourism is the use of ethnic cultural resources. Tourism in ethnic areas is mainly to develop and utilize ethnic cultural and natural resources, attract tourists through the unique attraction and charm of ethnic culture, and establish a tourist market. The original ecological culture of the Gelao tribe includes everything, including the ethnic villages, buildings, and various cultural monuments in the aforementioned residential culture of the Gelao tribe, as well as marriage customs and sacrificial culture. What is attractive to tourists is mainly the unique ancient ways of survival and lifestyle that are in the marginal state of life and the nonmainstream state of society, and are opposite to the modern age.

According to the needs of tourism development, transform the Gelao's apparent cultural resources into direct cultural capital, making it more attractive to modern tourists, and more conducive to attracting tourists to perceive and expe- 
rience the uniqueness and uniqueness of Gelao's original ecological culture, singularity, ancientity, nationality. The tourism development of the original ecological cultural resources of the Gelao people is a commercial activity and a part of industrialization. All the ancient lifestyles and forms that the Gelao people still retain can enter the tourism market and become products for tourists to perceive, experience, and consume. In this sense, the development of the original ecological cultural resources of the nation is comprehensive and all-round. All the original ecological cultural forms may become current resources for tourism development and may become consumer products in the tourism industry. But we have also seen that the needs of tourists are always a dynamic and changing form, a way of existence with differences. Not all primitive ecological cultures can be attractive to tourism, and not all primitive ecological cultural forms can be directly transformed into consumer products. Because the development of the original ecological cultural resources of the Gelao people should be a selective resource development.

Tourism in most ethnic areas is still in the stage of resource development and imitation. The added value of cultural resources has not been fully tapped, and it is often blindly developed based on its resources. However, how to advance further, expand the pure resource development into market-oriented development, and guide market development is an important issue facing the development of ethnic tourism. The development of the ecological and cultural resources of the Gelao people must face up to the existence of the ecological and cultural resources of the Gelao people, fully tap the value of this resource, transform potential resource advantages into obvious development advantages, transform resources into capital, and let culture develop Get a new life.

\section{Conclusion}

According to the relevant analysis of the original ecological cultural resources of the Gelao people, we can draw the following two conclusions:

First of all, the difference value, scarcity value and liveness value of the original ecological cultural resources of the Gelao people. The conclusion has the following enlightenment: minority areas are distributed in remote plateaus, mountains, droughts, disaster-prone areas, ecologically fragile and other special types of areas, so their original ecological cultural resources have their particularities. The particularity of the original ecological culture of the Gelao people directly affects the development and effectiveness of its resources.

Secondly, the development of the original ecological cultural resources of the Gelao people mainly refers to the development of tourism. This conclusion has the following enlightenment: The development of the national original ecological cultural resources is comprehensive and all-round. Therefore, all the original ecological cultural forms of the Gelao people may become resources for tourism development and may become consumer products in the tourism industry. But we have also seen that human needs are always a dynamic and changing form, a 
way of existence with differences. Not all the original ecological culture of the Gelao ethnic group can be attractive to people, and not all the original ecological cultural forms of the Gelao ethnic group can be directly transformed into consumer products.

\section{Conflicts of Interest}

The author declares no conflicts of interest regarding the publication of this paper.

\section{References}

Cai, C. Z., Zhang, W., \& Liang, Y. (2013). Gelao People's Original Ecological Culture: Spiritual Characteristics and Aesthetic Psychology. Ecological Economic Review, 185-199.

Huang, Z. H. (2017). The Third Line of Thought: The Combined Practice of the Protection of "Original Ecological Culture". Journal of Minzu University of China (Philosophy and Social Sciences Edition), 44, 124-131. https://www.cnki.net/kcms/doi/10.15970/j.cnki.1005-8575.2017.03.017.html

Li, X.-R., \& Zhang, X. (2013). An Analysis of the Coordination between Gelao Nationality's Traditional Customary Law and National Law. Journal of Zunyi Normal University, 15, 55-59.

Liu, M., \& Guo, R.-T. (2021). Research on Historical Memory, Landscape Symbols and the Construction of National Identity-Based on the Investigation of Landscape Symbols in the Gelao Villages of Guizhou. Journal of Guangxi University for Nationalities (Philosophy and Social Sciences Edition), 43, 108-116.

Xie, H.-L., Liu, Z.-F., \& Xu, B.-C. (2021). “Six-Chain Integration” Collaboratively Promotes the Realization of the Value of Ecological Products. Journal of China Land, 11, 32-35.

https://kns.cnki.net/kcms/detail/detail.aspx?doi=10.13816/j.cnki.ISSN1002-9729.202 $\underline{1.11 .11}$

Yu, D.-Z. (2011). The Value of Original Ecological Cultural Resources and Tourism Development-Taking Southeast Guizhou as an Example. Nationalities Publishing House.

Yuan, X.-Y. (2020). Research on the Spatial Form of the Traditional Village Settlement of Gelao People in Northern Guizhou. Master's Thesis, Southwest University. https://kns.cnki.net/kcms/detail/detail.aspx?doi=10.27684/d.cnki.gxndx.2020.003071\& $\mathrm{dbcode}=\mathrm{CMFD}$ 